\title{
Regulation of polyphenol oxidase activities and melanin synthesis in Marinomonas mediterranea: identification of ppos, a gene encoding a sensor histidine kinase
}

\author{
Patricia Lucas-Elío, ${ }^{1}$ Francisco Solano ${ }^{2}$ and Antonio Sanchez-Amat ${ }^{1}$
}

\begin{abstract}
Author for correspondence: Antonio Sanchez-Amat. Tel: +34 968 364955. Fax: +34968363963. e-mail: antonio@um.es
\end{abstract}

Department of Genetics and Microbiology, Faculty of Biology ${ }^{1}$ and Department of Biochemistry and Molecular Biology B2, University of Murcia, 30100 Murcia, Spain

\begin{abstract}
Marinomonas mediterranea is a melanogenic marine bacterium that expresses two different polyphenol oxidases. One of them is a multipotent laccase able to oxidize a wide range of substrates. The second enzyme is an SDS-activated tyrosinase. Using transposon mutagenesis, a mutant affected in the regulation of both polyphenol oxidase activities and melanogenesis has been isolated. The sequencing of the gene disrupted by the mini-Tn 10 transposon in this mutant indicates that it encodes a hybrid sensor kinase. This sensor kinase shows three phosphorylated conserved domains: the transmitter domain containing a histidine site typical of sensor kinases, a receiver domain with an aspartate residue and an additional phosphotransferase domain with a second conserved histidine. This structural organization is characteristic of kinases participating in a phosphorelay system. Northern blot and lacZ operon fusions indicate that the multipotent laccase activity is regulated not only by PpoS but also by growth phase at the transcriptional level. These results suggest that PPO activities and melanin synthesis play a role in the adaptive response of $M$. mediterranea to stressful environmental conditions.
\end{abstract}

Keywords: Marinomonas mediterranea, marine bacterium, two-component histidine kinase, laccase, tyrosinase

\section{INTRODUCTION}

Marinomonas mediterranea is a Gram-negative melanogenic marine bacterium recently isolated and classified by our group (Solano et al., 1997; Solano \& SanchezAmat, 1999). M. mediterranea expresses two different polyphenol oxidase (PPO) enzymes. One of them is a tyrosinase (EC 1.14.18.1) with tyrosine hydroxylase (TH) and 3,4-dihydroxyphenylalanine (L-dopa) oxidase activities that are strongly activated by SDS. This enzyme is involved in melanin synthesis as demonstrated by the fact that mutants affected in this activity are not

Abbreviations: Amp, ampicillin; DMP, dimethoxyphenol; DMPO, DMP oxidase; DO, dopa oxidase; Gm, gentamicin; Km, kanamycin; L-dopa, 3,4dihydroxyphenylalanine; PPO, polyphenol oxidase; RACE, rapid amplification of cDNA ends; Rif, rifampicin; SO, syringaldazine oxidase; $\mathrm{TH}$, tyrosine hydroxylase.

The GenBank accession number for the sequence reported in this paper is AF398464. melanogenic (Solano et al., 1997). The second enzyme is an unusual membrane-located, blue multi-copper laccase (EC 1.10.3.2) able to oxidize a wide range of substrates, including those characteristic for laccases, such as dimethoxyphenol (DMP) and syringaldazine, and also those characteristic for tyrosinases, L-tyrosine and L-dopa (Fernández et al., 1999; Sanchez-Amat \& Solano, 1997). The gene encoding this multipotent PPO, ppoA, has been cloned (Solano et al., 2000). The protein PpoA shows some extra histidine-rich copper-binding domains that are very likely related to its unique enzymic properties and the capacity to show that wide range of activities (Sanchez-Amat et al., 2001).

Laccases are enzymes with promising biotechnological applications. They have been intensively studied in fungi, where they have been related to a variety of physiological functions (Thurston, 1994). Among these functions, this enzyme is used to produce dopa-melanins in the presence of diphenolic compounds in the human pathogen Cryptococcus neoformans (Williamson et al., 
1998). In another fungus, Aspergillus fumigatus, a laccase participates in conidial pigment biosynthesis (Tsai et al., 1999).

By contrast, laccase activity has been rarely reported in prokaryotes (Givaudan et al., 1993; Solano et al., 1997). In Azospirillum lipoferum this enzymic activity was described for the first time in a bacterium (Givaudan et al., 1993). Although its physiological role is unknown, it has been related to melanin synthesis in this microorganism (Faure et al., 1994). Recently, there has been mounting evidence indicating that different bacterial blue multi-copper proteins also show some kind of laccase activity (Hullo et al., 2001; Kim et al., 2001; Solano et al., 2001). These proteins are involved in different cellular processes such as sporulation in Bacillus (Hullo et al., 2001) and copper resistance in Escherichia coli (Kim et al., 2001).

The physiological relevance of the laccase activity in $M$. mediterranea is unknown. Strain Tn101 is a null mutant in this activity obtained by transposon mutagenesis (Solano et al., 2001). The preliminary characterization of this mutant has not yet shown any relevant physiological alteration under standard culture conditions. These results suggest that this enzyme is not essential for bacterial growth in these conditions and it should rather play some role in the adaptation of $M$. mediterranea to some specific environmental conditions. Thus some regulatory elements should be involved in the connection between environmental stimuli and expression of PPO activities and we have initiated studies to address this point.

Two-component signal transduction systems regulate the adaptive responses of prokaryotic and eukaryotic micro-organisms to changing environmental conditions (Stock et al., 1989). In the more typical form, they are composed of two proteins: a histidine protein kinase, also called sensor kinase, and a response regulator. The sensor kinase is a membrane protein that senses environmental stimuli through its N-terminal input domain and undergoes autophosphorylation at a highly conserved histidine residue in the C-terminal transmitter domain. Subsequently, the phosphate group is transferred to an aspartic residue sited in the $\mathrm{N}$-terminal receiver domain of the response regulator. This change modulates the activity of the C-terminal output domain, generally with DNA-binding capacity, regulating gene expression in response to the stimulus.

Modified and more complex versions of the phosphoryl group-based transduction mechanism have been described (Appleby et al., 1996). One example is the fourstep phosphorelay system, in which the phosphoryl group is transferred in the order His-Asp-His-Asp with the phosphorylated amino acids in different domains. This phosphorelay system can show different structural organizations with the four conserved domains distributed in a variable number of proteins (Appleby et al., 1996). For instance, the process of sporulation in Bacillus subtilis was the first process regulated by the mechanism described and in this case the four phosphorylated domains are in four different proteins (Burbulys et al., 1991). Another example of a different organization is the BvgS-BvgA system that regulates virulence factors in Bordetella pertussis (Uhl \& Miller, 2001). This phosphorelay system is only composed of two proteins: BvgS is a hybrid tripartite sensor kinase since it is fused with a phosphoaspartate receiver domain plus a second phosphotransferase domain. BvgA is its associate response regulator containing the final domain with the Asp residue.

The aim of this work was to initiate the studies on the regulation of the expression of PPO activities in $M$. mediterranea. A mutant affected in the regulation of these processes has been obtained by transposon mutagenesis. The sequencing of the disrupted gene in this mutant has shown that it encodes a hybrid sensor kinase with the same organization as BvgS. This sensor kinase regulates both laccase and tyrosinase activities, as well as melanin synthesis, indicating a relationship between these processes in $M$. mediterranea at least at the regulatory level.

\section{METHODS}

Bacterial strains, plasmids and growth conditions. The bacterial strains and plasmids used in this study are listed in Table 1. E. coli strains were grown in Luria-Bertani medium. M. mediterranea was usually grown in Marine Broth, Agar 2216 (Difco) or MMC (Fernández et al., 1999). In the experiments of nutrient starvation, cells were suspended in SST, a Tris-buffered saline solution reproducing the more important salts present in sea water (Solano et al., 1997). When required, media were supplemented with the appropriate antibiotic and/or X-Gal. Inorganic salts to prepare buffers and culture media were from Merck. Peptones and yeast extract were from Oxoid. All substrates for the enzymic assays and the antibiotics were from Sigma, except 2,6dimethoxyphenol (DMP), which was from Fluka Chemie.

Transposon mutagenesis and screening for mutants affected in PPO regulation. Plasmid $\mathrm{pLOFKm}$ containing a mini-Tn10 transposon derivative encoding kanamycin $(\mathrm{Km})$ resistance

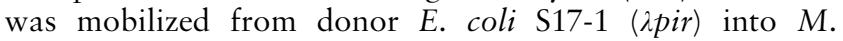
mediterranea by conjugation as previously described (Solano et al., 2000). Exconjugants containing the transposon were selected by plating on MMC medium with rifampicin $\left(50 \mu \mathrm{g} \mathrm{ml}^{-1}\right)$ and kanamycin $(\mathrm{Km})\left(50 \mu \mathrm{g} \mathrm{ml}^{-1}\right)$. Those strains were allowed to grow for 3 or 4 days and then replicated using a toothpick on MMC and DMP plates (Solano et al., 2000). Laccase activity was detected by the quick appearance of a bright orange colour on the DMP plate. Putative regulatory mutants were those showing a lower level, but not a complete absence, of DMP oxidase (DMPO) activity.

Southern blotting. Chromosomal DNA was extracted from several independent $M$. mediterranea rifampicin-resistant $\left(\mathrm{Rif}^{\mathrm{r}}\right)$, ampicillin-sensitive $\left(\mathrm{Amp}^{\mathrm{s}}\right), \mathrm{Km}^{\mathrm{r}}$ transconjugants ob-

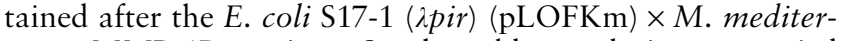
ranea MMB-1R matings. Southern blot analysis was carried out after digesting these samples with different restriction enzymes. A digoxigenin-labelled NotI fragment from pLOFKm encompassing the kanamycin-resistance gene was used as a probe to check transposon insertion. 
Table 1. Strains, plasmids, transposons and primers used

\begin{tabular}{|c|c|c|}
\hline $\begin{array}{l}\text { Strain, plasmid } \\
\text { or primer }\end{array}$ & Description and/or relevant genotype & Source or reference \\
\hline \multicolumn{3}{|l|}{ Strains } \\
\hline \multicolumn{3}{|l|}{ M. mediterranea } \\
\hline MMB-1 & Wild-type, Rifs, Gm ${ }^{\mathrm{s}}$ & Solano et al. (1997) \\
\hline MMB-1R & MMB-1, spontaneously Rif ${ }^{r}$ & Solano et al. (2000) \\
\hline T103 & MMB-1R ppoS:: $\operatorname{Tn} 10(\mathrm{Km})$ & This study \\
\hline MMB1LAC0 & MMB-1R $\Omega$ mini-Tn10 $\mathrm{Gm}^{\mathrm{r}}\left(\operatorname{trp}^{\prime}-{ }^{\prime} l a c Z\right)$ & This study \\
\hline MMB1LAC1 & MMB-1R $\Omega$ mini-Tn10 $\mathrm{Gm}^{\mathrm{r}} \phi(p p o A-l a c Z)$ & This study \\
\hline T103LAC0 & $\mathrm{T} 103 \Omega$ mini-Tn10 $\mathrm{Gm}^{\mathrm{r}}\left(\operatorname{trp}^{\prime}-{ }^{\prime} \operatorname{lac} Z\right)$ & This study \\
\hline T103LAC1 & $\mathrm{T} 103 \Omega$ mini-Tn10 $\mathrm{Gm}^{\mathrm{r}} \phi(p p o A-l a c Z)$ & This study \\
\hline \multicolumn{3}{|l|}{ E. coli } \\
\hline S17-1 (ipir) & 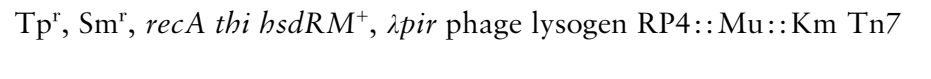 & $\begin{array}{l}\text { V. de Lorenzo, Centro Nacional de } \\
\text { Biotecnologia, Madrid, Spain }\end{array}$ \\
\hline $\mathrm{DH} 5 \alpha$ & & Invitrogen \\
\hline \multicolumn{3}{|l|}{ Plasmids } \\
\hline pUCT103 & $\begin{array}{l}\mathrm{Ap}^{\mathrm{r}}, \mathrm{Km}^{\mathrm{r}} ; \mathrm{pUC19}+9 \mathrm{~kb} \text { EcoRI fragment of chromosomal DNA from } \\
\text { strain T103 }\end{array}$ & This study \\
\hline pLOFKm & ori $\mathrm{R} 6 \mathrm{~K}$, mob $\mathrm{RP} 4, \mathrm{Ap}^{\mathrm{r}}$, mini- $\mathrm{Tn} 10 \mathrm{Km}^{\mathrm{r}}$, delivery vector & Herrero et al. (1990) \\
\hline pBSL182 & ori $\mathrm{R} 6 \mathrm{~K}$, mob $\mathrm{RP} 4, \mathrm{Ap}^{\mathrm{r}}$; mini-Tn10 $\mathrm{Gm}^{\mathrm{r}}$, delivery vector & Alexeyev et al. (1995) \\
\hline pUJ8 & $A p^{r}, t^{\prime} p^{\prime}-{ }^{\prime} l a c Z$ & de Lorenzo et al. (1990) \\
\hline pUJ8ppoA & pUJ8, $\phi(p p o A-l a c Z)$ & This study \\
\hline pBFU8 & pBSL182, mini-Tn10 $\mathrm{Gm}^{\mathrm{r}} \phi(p p o A-l a c Z)$, delivery vector & This study \\
\hline pBGAL & pBSL182, mini-Tn10 $\mathrm{Gm}^{\mathrm{r}}$ (trp'-'lacZ), delivery vector & This study \\
\hline pBKSII & & Stratagene \\
\hline pUC19 & & New England Biolabs \\
\hline pPEN & $\mathrm{Ap}^{\mathrm{r}}, \mathrm{pBKSII}+1.4 \mathrm{~kb}$ EcoRI-NotI fragment from pUCT103 & This study \\
\hline PGEN & $\mathrm{Ap}^{\mathrm{r}}, \mathrm{pBKSII}+5.8 \mathrm{~kb}$ EcoRI-NotI fragment from pUCT103 & This study \\
\hline pGENHIND & $\mathrm{Ap}^{\mathrm{r}}$, pUC19+1·1 kb HindIII-NotI fragment from pUCT103 & This study \\
\hline pGENCLA & $\mathrm{Ap}^{\mathrm{r}}, \mathrm{pBKSII}+2 \cdot 3 \mathrm{~kb}$ ClaI-NotI fragment from pUCT103 & This study \\
\hline Primers & Sequence (engineered restriction sites underlined) & \\
\hline PPOSP1 & 5'-CAAGGCTGTCCATGTTGCGACG-3' & \\
\hline PPOSP2 & 5'-GCAGTGACATTGAGCAAGGCG-3' & \\
\hline PPOSP3 & 5'-AACCAGCCGGATCCCTGTGGAACGC-3' & \\
\hline ECOFUF & 5'-CTGACTGCGAATTCATTGATTGC-3' & \\
\hline BAMFUR & 5'-CAGTATCAGGATCCATTTCAGC-3' & \\
\hline DIRECT & 5'-GAGCTAAACTTTCATATGTCTGTCGC-3' & \\
\hline REVTRUN & 5'-CAGTATCAGGATCCATTTAAGCAAT-3' & \\
\hline
\end{tabular}

Cloning of the ppos gene. Isolated genomic DNA of $M$. mediterranea T103 was digested with EcoRI and ligated to pUC19 digested with the same enzyme. The ligation mixture was transformed into E. coli $\mathrm{DH} 5 \alpha$ and transformants selected for ampicillin and kanamycin resistance. The plasmid obtained (pUCT103) was subcloned in pBKS II by using the NotI restriction sites that the transposon has close to both ends of IS10 and the EcoRI, ClaI and HindIII restriction sites in the M. mediterranea chromosome DNA. The DNA adjacent to the insertion point was sequenced using the T3 and T7 universal primers as well as some internal primers synthesized as required.

RNA extraction and Northern blot analysis. M. mediterranea strains were inoculated in MMC, and two samples were taken, one at mid-exponential phase $\left(\mathrm{OD}_{600}\right.$ around $\left.0 \cdot 3\right)$ and another at early stationary phase $\left(\mathrm{OD}_{600}\right.$ around $\left.0 \cdot 9\right)$. Total RNA was extracted from M. mediterranea MMB-1R and T103 by standard protocols (Chirgwin et al., 1979). Ten micrograms of RNA were denatured by treatment with DMSO and glyoxal. The denatured RNA samples were electrophoresed through a $1 \%$ agarose gel in $10 \mathrm{mM}$ phosphate running buffer, $\mathrm{pH}$ 7. Prior to blotting, certainty of equal sample loadings was verified by equivalent intensities of the $16 \mathrm{~S}$ and $23 \mathrm{~S}$ rRNA bands in all samples after acridine orange staining. RNA was transferred to a nylon transfer membrane Hybond- $\mathrm{N}^{+}$(Pharmacia) by downward capillary and fixed by UV irradiation. The $p p o A$ probe was generated by PCR using the primers DIRECT and REVTRUN (Table 1) which encompassed a $1.2 \mathrm{~kb}$ fragment close to the $5^{\prime}$ end of the gene. The ppoA probe was radioactively labelled with $\left[\alpha^{3}{ }^{32} \mathrm{P}\right] \mathrm{dATP}$ by use of a random-primed DNA labelling kit (Boehringer) according to the manufacturer's protocol. The labelled probe was purified by gel filtration in Sephadex G-25 columns (Pharmacia). Prehybridization and hybridization were carried 


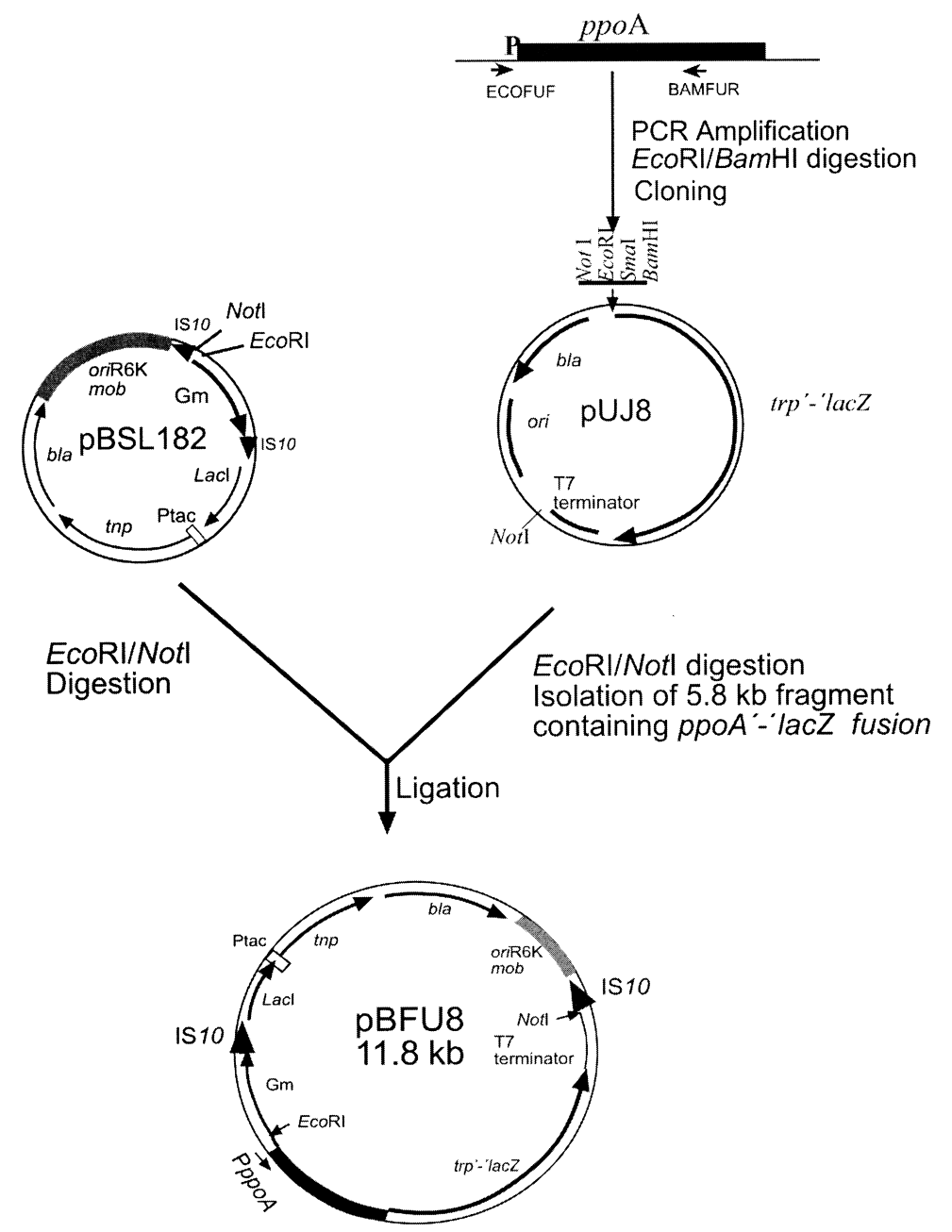

Fig. 1. Construction of pBFU8. A PCR product carrying the promoter region upstream of $p p o A$ was generated by amplification of $M$. mediterranea genomic DNA with primers ECOFUF and BAMFUR. This product was cloned in plasmid pUJ8. The resulting plasmid, pUJ8ppoA, was digested with ECORI and Notl and cloned into the mini-Tn10 transposon in plasmid pBSL182, generating pBFU8. This plasmid contains a transposon derivative with a transcriptional fusion between the $p p o A$ and the lacZ genes. A control plasmid pBGAL was created in the same way, but from pJU8 instead of pUJ8ppoA and hence contains a transposon with a promoterless lacZ.

out at $42{ }^{\circ} \mathrm{C}$. The prehybridization solution contained $50 \%$

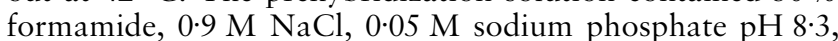
$5 \mathrm{mM}$ EDTA, $5 \times$ Denhardt's reagent $(0 \cdot 1 \%$ Ficoll and $0 \cdot 1 \%$ polyvinylpyrrolidone), $0.3 \%$ SDS, $0.2 \mathrm{mg} \mathrm{BSA} \mathrm{ml}^{-1}$ and $0.25 \mathrm{mg}$ denatured herring sperm $\mathrm{DNA} \mathrm{ml} \mathrm{m}^{-1}$. The hybridization solution had the same composition plus $10 \%$ dextran sulfate and the labelled probe previously denatured at $100{ }^{\circ} \mathrm{C}$ for $5 \mathrm{~min}$. Radioactive bands were visualized using the Molecular Imager System GS-525 (Bio-Rad) with the Molecular Analyst software (Bio-Rad).

Mapping the ppoS transcriptional start site. To locate the transcriptional start of the $p$ poS gene, $5^{\prime}$ rapid amplification of cDNA ends (RACE) experiments were carried out using a 5'/3' RACE Kit essentially as recommended by the manufacturer (Roche Molecular Biochemicals). Total RNA (2 $\mu \mathrm{g}$ ) isolated from $M$. mediterranea at the stationary phase in MMC was reverse transcribed with the $p$ poS-specific primer PPOSP1 (see Table 1) which anneals 793-814 bp downstream of the $p$ poS translational start site. A control reaction without reverse transcriptase was included to ensure that the resulting product was due to the amplification of cDNA rather than contaminating chromosomal DNA. A poly(dA) tail was appended to the $3^{\prime}$ end of the cDNA using terminal transferase and PCR amplified using the RACE oligo(dT)-anchor primer and a nested $p$ poS-specific primer PPOSP2. The PCR product obtained was again PCR amplified with a kit-provided PCR anchor primer containing a ClaI site and a nested ppoSspecific primer PPOSP3 modified to introduce a BamHI restriction site. This last primer anneals $452-476$ bp downstream of the $p p o S$ translational start. The resulting product was purified using a High Pure PCR product purification kit (Roche Diagnostics), cloned into the pBKSII vector at the ClaI/BamHI sites and sequenced.

Single-copy transcriptional fusion construction. Plasmid pBFU8 containing a transcriptional fusion between $p p o A$ and the $l a c Z$ gene was created using the auxiliary plasmid pUJ8 (de Lorenzo et al., 1990). The construction process is outlined in Fig. 1. A PCR product carrying $135 \mathrm{bp}$ upstream of the translational start of $p p o A$, and hence comprising the promoter region and extending into the coding region, was generated by amplification of $M$. mediterranea genomic DNA with primers ECOFUF and BAMFUR (Table 1). This product was digested with EcoRI and BamHI cutting in the restriction sites introduced in the primers, and cloned between the corresponding sites of the plasmid pUJ8, generating a transcriptional fusion with the lac $Z$ gene. The whole fusion was excised as an EcoRI-NotI fragment and inserted into the corresponding sites of the mini-Tn10 transposon present in the plasmid pBSL182 (Alexeyev \& Shokolenko, 1995), generating the plasmid pBFU8. A control plasmid named pBGAL was also created. pBGAL and pBFU8 were identical except that the former did not contain the fragment derived from the 
chromosome of $M$. mediterranea and hence the lac $Z$ gene is promoterless. In both cases the lac $Z$ gene is in the opposite orientation to the gentamicin $(\mathrm{Gm})$-resistance marker of the transposon (Fig. 1). The transposons were transferred from donating E. coli into M. mediterranea MMB-1R and T103 by transposon mutagenesis as previously described (Solano et al., 2000). Mutant strains that were Rifr ${ }^{r} \mathrm{Gm}^{\mathrm{r}}$, and Amp ${ }^{\mathrm{s}}$ with a single copy chromosomal insertion of the transposon were selected.

Enzymic determinations. Total cell extracts were prepared as previously described (Solano et al., 1997). TH and dopa oxidase (DO) activities were determined by monitoring, respectively, the oxidation of $2 \mathrm{mM}$ L-tyrosine and L-dopa at $475 \mathrm{~nm}$ in $0 \cdot 1 \mathrm{M}$ phosphate buffer $\mathrm{pH} 5 \cdot 0$. For TH activity, $25 \mu \mathrm{M}$ L-dopa was added to the assay mixture to eliminate the lag period (Solano et al., 1997). When required, the activities were also assayed in the presence of $0.02 \%$ SDS $\left(\mathrm{TH}_{\mathrm{SDS}}\right.$ and $\mathrm{DO}_{\mathrm{SDS}}$, respectively). DMPO and syringaldazine oxidase (SO) activities were determined, respectively, by monitoring the oxidation of $2 \mathrm{mM}$ DMP at $468 \mathrm{~nm}$ in $0 \cdot 1 \mathrm{M}$ sodium phosphate buffer, $\mathrm{pH} 5 \cdot 0$, or the oxidation of $50 \mu \mathrm{M}$ syringaldazine at $525 \mathrm{~nm}$ in pH 6.5 (Solano et al., 1997). Reference cuvettes always had the same composition except for the enzymic extract. In all cases, one unit was defined as the amount of enzyme that catalyses the appearance of $1 \mu \mathrm{mol}$ product per min at $37^{\circ} \mathrm{C}$. Specific activities were normalized by $\mathrm{mg}$ protein, measured using the bicinchoninic acid kit (Pierce Europe). $\beta$-Galactosidase activities, expressed as Miller Units, were determined as previously described (Miller, 1992).

\section{RESULTS}

\section{Isolation of a $M$. mediterranea transposon mutant affected in the regulation of PPO activities and melanin synthesis}

M. mediterranea was mutagenized using the plasmid pLOFKm (Herrero et al., 1990), containing a mini-Tn10 $\mathrm{Km}^{\mathrm{r}}$ derivative that previously showed a high frequency of transposition in this micro-organism (Solano et al., 2000). To detect mutants affected in the regulation of laccase activity, we needed an easy protocol to detect alterations in the levels of this enzyme activity in the mutants generated. After mutagenesis, the strains were allowed to grow for several days in MMC complex medium. Several thousand mutants were qualitatively screened for laccase activity using DMP plates (Solano et al., 2000). In addition, the pigmentation of the colonies was also examined since amelanogenic mutants will be putatively affected in tyrosinase levels (Solano et al.,

Table 2. Specific PPO activities $\left(\mathrm{mU} \mathrm{mg}^{-1}\right)$ in cellular extracts from M. mediterranea MMB-1R and T103

\begin{tabular}{|lrr|}
\hline Activity & MMB-1R & T103 \\
\hline TH & $15 \cdot 2$ & $2 \cdot 3$ \\
TH $_{\text {SDS }}$ & $102 \cdot 6$ & $14 \cdot 7$ \\
DO & $66 \cdot 2$ & $11 \cdot 7$ \\
DO & $226 \cdot 1$ & $36 \cdot 6$ \\
DMPS & $105 \cdot 9$ & $17 \cdot 6$ \\
SO & $77 \cdot 1$ & $14 \cdot 5$ \\
\hline
\end{tabular}

1997; López-Serrano et al., 2002). One mutant, strain T103, which showed a significant decrease in laccase activity, was detected. Moreover, it was observed that this mutant was also impaired in melanin synthesis which was only appreciated after long periods of incubation of the cultures.

The mutant obtained was grown in liquid MMC medium and all the PPO enzymic activities so far detected in $M$. mediterranea were quantitatively determined in cellular extracts (Table 2). The results obtained indicated that, consistent with the screening method, the mutant showed a significant decrease in the laccase activities (DMPO and SO) due to the multipotent PpoA, as well as in the SDS-activated tyrosinase-related activities. This pattern strongly suggested that a regulatory gene would be affected in the selected mutant.

\section{Cloning and sequence analysis of the gene mutated in strain T103}

Chromosomal DNA was extracted from this mutant and Southern blotting revealed that it contained a single transposon insertion (data not shown). The chromosomal region flanking the transposon inserted in mutant T103 was cloned by marker rescue. Chromosomal DNA was digested with EcoRI and ligated to pUC19 digested with the same restriction enzyme. E. coli DH5 $\alpha$ was transformed with the ligation mixture and the transformants were selected for resistance to ampicillin and kanamycin, plasmid and transposon markers, respectively. A plasmid, designated pUCT103, was obtained. This plasmid contained an EcoRI insert of approximately $9 \mathrm{~kb}$ (Fig. 2).

Sequencing of the chromosomal region around the site of transposon insertion revealed that the transposon interrupted an ORF of $2817 \mathrm{bp}$ encoding a putative translation product of 938 aa. The gene was named $p p o S$ for PPO sensor kinase (GenBank accession number AF398464). The ORF starts with an ATG codon that may code for the initial methionine. Six base pairs upstream from this codon, a putative ribosome-binding site was detected (GGAAG) (Fig. 3). To map precisely the transcriptional start point of the $p p o S$ gene, the RACE protocol was applied as described in Methods. Using this protocol, we observed a $5^{\prime}$ RACE product of $520 \mathrm{bp}$. This product was cloned in pBKSII. Sequencing of this fragment revealed that it shows a $5^{\prime}$ end matching perfectly with the upstream sequence of $p$ poS (Fig. 3). The $G$ following the poly $(T)$ has very likely been duplicated during the process of amplification as described elsewhere (Chen \& Patton, 2001). According to this result, the $\mathrm{G}$ residue located $35 \mathrm{nt}$ upstream of the ppoS initial ATG could be identified as the start of transcription (Fig. 3). Analysis of the upstream sequence offers several possibilities for the promoter sequence. The sequence CTAGTCT shows a good match to the -10 consensus sequence for $\sigma^{70}$ promoters in the three underlined nucleotides that are the more highly conserved. Interestingly, this sequence shows a higher similarity to the new $\sigma^{38}, r p o S$, consensus, CTATACT, 


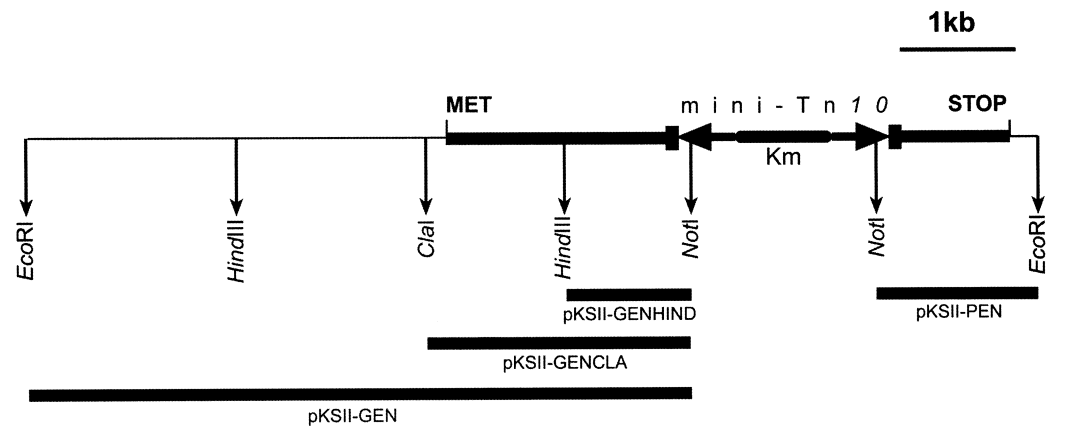

Fig. 2. Genetic map of the chromosomal region surrounding the site of insertion of the mini-Tn10 transposon in strain T103. Relevant restriction sites are marked. The fragments subcloned in different plasmids are indicated at the bottom.

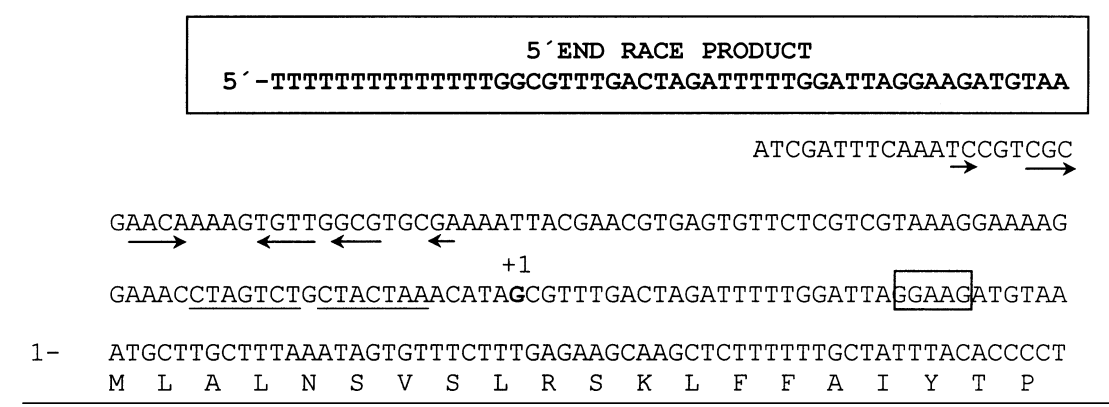

Fig. 3. Nucleotide sequence of the ppos regulatory region plus the beginning of the ORF. The transcriptional start site $(+1)$, the two putative -10 regions (underlined) and the ribosome-binding site (boxed) are indicated. Arrows indicate a palindromic sequence. Above the sequence, the $5^{\prime}$ end of the RACE product is shown.

Table 3. Alignment of conserved domains in the hybrid tripartite sensor kinases

$\mathrm{H} 1$, primary transmitter domain; D1, receiver domain; H2, secondary transmitter domain. The phosphorylated residues are in bold type. The GenBank accession number is shown in parentheses.

\begin{tabular}{|c|c|c|c|c|}
\hline Protein & H1 & D1 & $\mathrm{H} 2$ & Total length \\
\hline PpoS (AF398464) & 292 KSQFLANISHEIRTPLNAI & 738 DLILMDIQMPEMDG & 879 VHRLHG & 938 \\
\hline GacS (B41863) & 297 KSEFLANMSHEIRTPLNGI & 723 DLVLMDVQMPGMDG & 874 IHRLHG & 929 \\
\hline BvgS (M25401) & 721 KTTFLATMSHEIRTPMNAI & 1018 DVVITDCNMPGISG & 1171 AHRLAG & 1238 \\
\hline EvgS (D14008) & 711 KSQFLATMSHEIRTPISSI & 1004 DLLITDVNMPNMDG & 1136 IHRIHG & 1197 \\
\hline BarA (D10888) & 293 KSEFLANMSHEIRTPLNGV & 713 DLILMDIQMPDMDG & 860 IHKLHG & 918 \\
\hline TorS (X94231) & 434 KSAFLAAMSHEIRTPLYGI & 718 AAALVDFDLPDIDG & 849 AHQLKS & 943 \\
\hline $\operatorname{ArcB}(\mathrm{X} 53315)$ & 283 KTTFISTISHELRTPLNGI & 571 DLVLLDIQLPDMTG & 716 GHKIKG & 777 \\
\hline
\end{tabular}

recently proposed (Lee \& Gralla, 2001). However, it is centred at an unusual distance of about $16 \mathrm{nt}$ from the transcriptional start site. Alternatively, the sequence CTACTAA, located around -10 and also resembling the $\sigma^{38}$ consensus, could act as the promoter -10 region. The -35 region was not so clearly detectable, which could be explained if this were a $\sigma^{38}$-regulated promoter.

Analysis of the coding region sequence showed that ppoS encodes a member of the family of proteins participating in the phosphoryl-group signal transduction system. PpoS seems to be a composite sensor kinase that contains, in addition to the transmitter domain, a response regulator receiver domain and a second phosphotransferase domain, similar to BvgS and related kinases (Table 3). Sequence analysis (Cserzo et al., 1997) has detected two transmembrane regions between amino acids 17-31 and 181-197, respectively, in agreement with the characteristic membrane location of this kind of sensor kinase.

\section{Regulation of PPO expression in M. mediterranea: effect of the PpoS mutation}

The effect of the PpoS mutation in the regulation of the laccase and tyrosinase activities was followed by a comparative study of these activities during the growth curve of the wild strain MMB-1R and the mutant strain T103 in MMC medium. First of all, under these conditions both strains showed a very similar growth rate, suggesting that PpoS is not involved in any process 

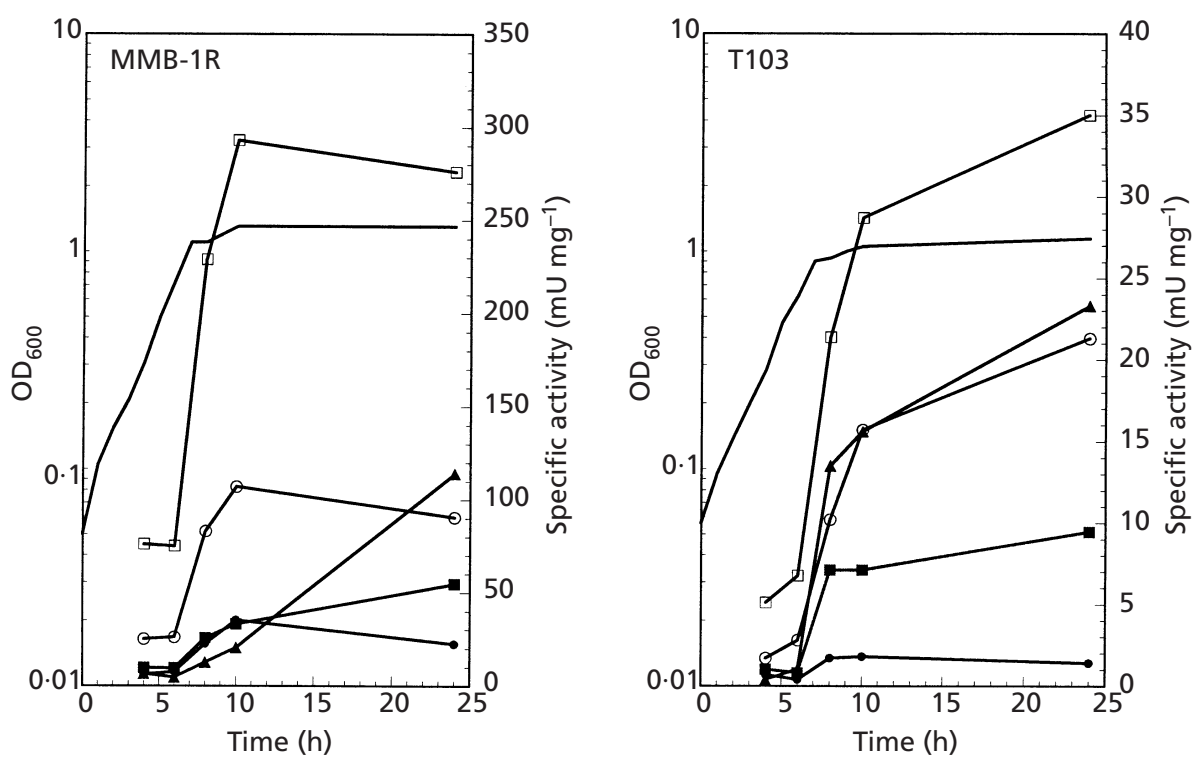

Fig. 4. $P P O$ activities during growth of $M$. mediterranea MMB-1R and $T 103$ in $M M C: T H(O) ; T_{S D S}(O) ; D O(\mathbb{\square}) ; D O_{S D S}$ $(\square)$; DMPO $(\boldsymbol{\Delta})$. The lines with no marks represent growth, which is equal in both strains, measured as $\mathrm{OD}_{600}$.

essential for cell growth and division (Fig. 4). The main difference observed between both strains was that all the enzymic levels were always lower in strain T103 than in strain MMB-1R (Fig. 4). However, with respect to the time-course, the patterns of PPO expression were very similar in both strains, the PPO activities being growthphase regulated and induced when the cultures approached the stationary phase of growth (Fig. 4). The induction of PPO activities in these conditions is very likely due to nutrient depletion, since PPO activities were also induced when cells in the mid-exponential phase of growth were subjected to nutrient starvation, after being washed and suspended in SST (data not shown).

The effect of the mutation of the $p p o S$ gene on the regulation of the multipotent laccase PpoA was studied in more detail. The level of $p p o A$ mRNA was determined by Northern blotting in strains MMB1-R and T103. It was observed that in strain MMB1-R, but not in strain T103, there was a significant increase in mRNA levels at the stationary phase (Fig. 5). The higher molecular mass band correlates with the expected size of the transcript of the $p p o A$ gene; around $2 \cdot 1 \mathrm{~kb}$ (SánchezAmat et al., 2001).

To further explore the transcriptional regulation of the ppoA gene, lac fusions to this gene were created as described in Methods (Fig. 1). M. mediterranea MMB1$\mathrm{R}$ and T103 were mutagenized using the mini-Tn10 $\mathrm{Gm}^{\mathrm{r}}$ transposons created in plasmids pBFU8 and pBGAL. Mutant strains $\mathrm{Rif}^{\mathrm{r}}, \mathrm{Gm}^{\mathrm{r}}$ and $\mathrm{Amp} \mathrm{p}^{\mathrm{s}}$ with a single copy chromosomal insertion of the transposon were selected. Four representative strains were selected: MMB1LAC1, MMB1LAC0, T103LAC1 and T103LAC0, where LAC1 strains were the result of the mutagenesis with plasmid

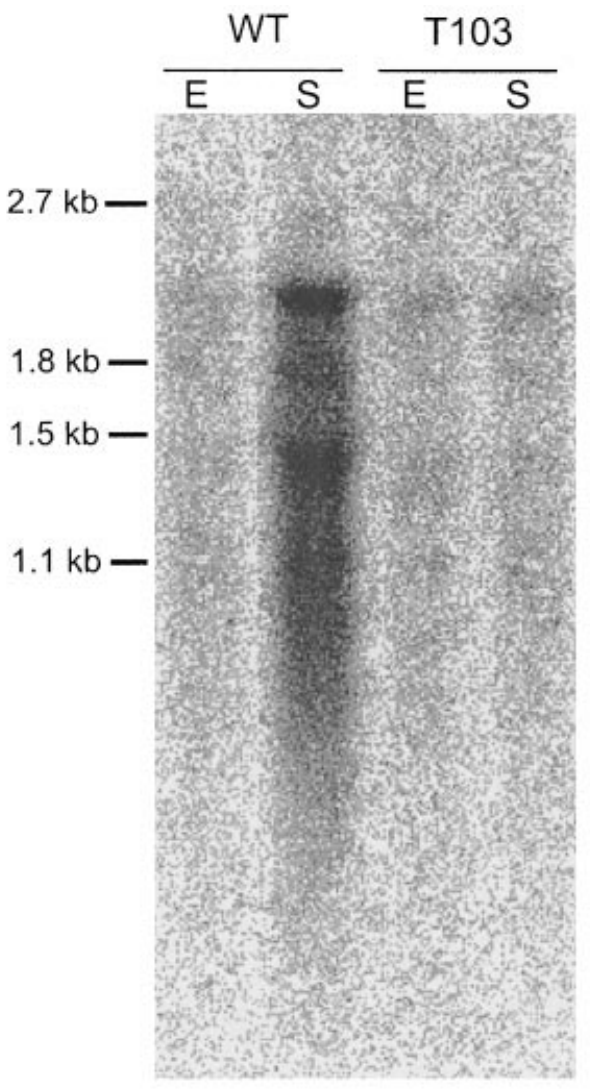

Fig. 5. Northern hybridization of RNA extracted from $M$. mediterranea MMB1-R and T103. Samples were taken during exponential (E) and stationary (S) phases of growth in MMC. Equal amounts of total RNA $(10 \mu \mathrm{g})$ were separated on agarose gels, transferred onto positively charged nylon membrane and hybridized with a ${ }^{32} \mathrm{P}$-labelled probe specific for $p p o A$. 


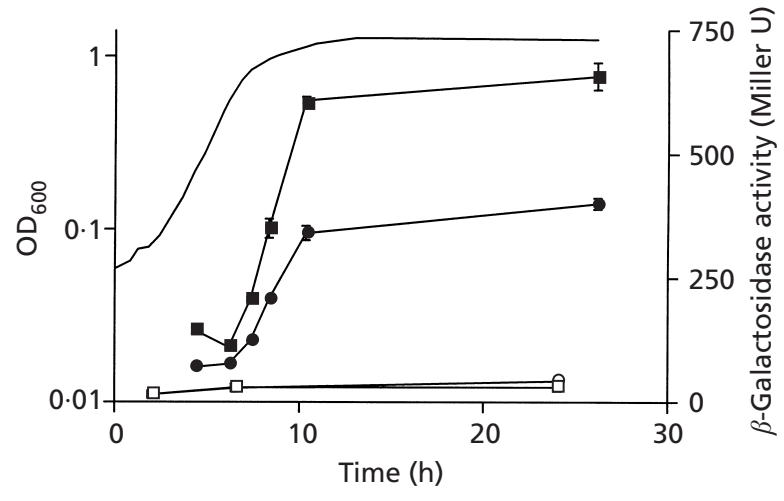

Fig. 6. $\beta$-Galactosidase activities of different $M$. mediterranea strains during the growth curve in MMC: MMB1LAC1 ( $\square$ ), T103LAC1 (0), MMB1LAC0 ( $\square$ ) and T103LAC0 (O). The line with no marks represents growth, equal in both strains, measured as $\mathrm{OD}_{600}$.

pBFU8 and hence contain a $p p o A-l a c Z$ fusion. LAC0 strains were mutagenized with control plasmid pBGAL, and the lac $Z$ gene is promoterless.

The strains MMB1LAC0 and T103LAC0, obtained with the control plasmid pBGAL, showed very low levels of $\beta$ galactosidase activity (Fig. 6). This result agrees with the absence of promoter driving lac $Z$ expression in the construct, and also indicates that its expression is not dependent on the genetic background of the strain mutagenized or the site of insertion. The opposite orientation of the gentamicin-resistance marker with respect to lac $Z$ may contribute to the absence of reading from promoters located outside the construction.

The strains containing a single copy of a transcriptional ppoA-lac $Z$ fusion showed high $\beta$-galactosidase levels that were growth-phase regulated (Fig. 6). Strain MMB1LAC1 showed a slightly higher level of $\beta$ galactosidase expression, less than twofold, than strain T103LAC1. The PPO activities were also measured in these strains, and it was observed that the insertion of the transposon containing the fusion did not modify significantly those activities. In agreement with the results shown in Fig. 4, the strain derived from MMB-1R showed higher levels of PPO activities than the strain derived from T103 (data not shown).

\section{DISCUSSION}

M. mediterranea is a prokaryotic marine micro-organism where an active melanogenesis takes place when the cultures reach the stationary phase in complex or chemically defined medium containing tyrosine. The bacterium contains a tyrosinase, the main enzyme involved in melanin formation in standard culture conditions, and also a second PPO. This last PPO, PpoA, is a membrane-bound laccase-like enzyme able to oxidize a wide range of substrates including L-tyrosine. To understand the possible relationship between the two enzymes, and the physiological relevance of the laccase activity, it is important to characterize the elements involved in its regulation.

After transposon mutagenesis, we isolated a M. mediterranea mutant, strain T103, that was affected in laccase activity as well as in tyrosinase activity and melanin formation. Quantitative determinations on cellular extracts from this mutant showed a significant decrease in all the enzymic activities described in this microorganism, that is those due to the multipotent laccase PpoA, as well as those due to the SDS-activated tyrosinase (Table 2). Both enzymes also had in common that they were growth-phase regulated in a similar fashion (Fig. 4). These results clearly indicate that both enzymes are subjected to some coordinate regulatory mechanisms that induce their expression under specific conditions.

The gene mutated in strain T103 has been cloned and sequenced. According to BLAST homology search and sequence analysis, this gene encodes a sensor kinase belonging to a two-component regulatory system and hence it has been denominated ppoS. Two-component signal transduction systems have been described in many different prokaryotic micro-organisms and also in some eukaryotic organisms (Appleby et al., 1996). These systems control many different cellular processes (Stock et al., 1989). However, this is the first example showing the involvement of these systems in the regulation of PPO activities or melanin synthesis.

As judged by the conserved domains contained in the PpoS sequence, this protein is a new member of the tripartite hybrid sensor kinase, since it shows three phosphorylable domains, H1, D1 and H2 (Table 3). This kind of sensor kinase participates in the multi-step phosphorelay, in which four phosphorylation events occur sequentially (Appleby et al., 1996). They should work in association with another member of the twocomponent systems, the response regulator that contains a conserved final Asp in the fourth phosphorylated domain. This second protein should be involved in the interaction with the DNA and the transcriptional regulation of other genes. However, in spite of our attempts, the response regulator in $M$. mediterranea remains to be identified.

The sensor kinases are membrane proteins and in fact sequence analysis indicated that PpoS contains two transmembrane domains that must encompass a segment facing the periplasmic space. This segment should receive the environmental signal that triggers the first autophosphorylation leading to the adaptive response (Stock et al., 1989). An extensive search through the databases using the sequence of the periplasmic fragment of the M. mediterranea PpoS did not allow the identification of any sensor kinase showing similarity to it in that region. Similarly, the comparison between sensor kinases of B. subtilis and E. coli did not reveal similarities in the periplasmic regions, which was considered to reflect the different environments that those organisms occupy (Fabret et al., 1999). In this 
regard, the marine environment from which $M$. mediterranea was isolated is a very different ecological niche. In addition, no information could be obtained using the whole sequence, since the proteins in the databases showing the highest identities to PpoS were GacS (LemA) of Pseudomonas syringae and BarA of E. coli, which showed identities as low as 29 and $28 \%$, respectively.

According to the results shown in Fig. 4, there is a growth-phase regulation affecting both the multipotent laccase PpoA and the SDS-activated tyrosinase. PpoS does not seem to participate in the growth-phase regulation of PPO activities, since in the mutated strain T103 lower PPO activities are observed, but the growthphase regulation is not suppressed. Data obtained with lacZ transcriptional fusions and Northern blots indicate that, at least for the $p p o A$ gene, the regulation is at the transcriptional level. It is important to point out that the proposed promoter for $p$ po $A$ shows a -10 region, CTAGTC (Sanchez-Amat et al., 2001), identical to one of the putative regions in the $p$ poS promoter and also resembling the $\sigma^{38}$ consensus (Lee \& Gralla, 2001). These results strongly suggest that the growth-phase regulation could be controlled by an alternative sigma factor, such as $\sigma^{38}$. On the other hand, wild-type and T103 fusion strains show $\beta$-galactosidase levels differing only by a factor of approximately two; this small difference can not justify the big difference between the two strains in the amount of PpoA RNA observed by Northern blot or in the enzymic activities. This discrepancy suggests that there is a similar transcriptional rate of the $p p o A$ promoter in both strains and that the involvement of PpoS in the regulation of PpoA occurs at the post-transcriptional level. One likely possibility is that PpoS enhances factors stabilizing the $p p o A$ transcript, as proposed for the regulation of BarA expression by RpoS (Mukhopadhyay et al., 2000).

The coordinate regulation of both enzymes under stress conditions, such as reaching the stationary phase, suggests that they may form part of the adaptive response of $M$. mediterranea to these kinds of conditions. In this regard, melanin pigments are considered to be important factors in the resistance against stress factors such as UV radiation and oxidative damage. Under standard laboratory conditions we have shown that the important enzyme in melanin synthesis by $M$. mediterranea is the SDS-activated tyrosinase, which uses as substrate the tyrosine present in the culture medium (Solano et al., 1997; López-Serrano et al., 2002). However, the substrate used for melanin synthesis in sea waters, the natural environment from which M. mediterranea was isolated, is unknown. It is important to bear in mind that although in marine waters it is possible to find some enriched microenvironments, such as surface biofilms, the mean amino acid concentration is in the range of 10-30 $\mathrm{nM}$ (Lee \& Bada, 1975). In this context, the wide range of substrates that the multipotent laccase is able to oxidize may be important to facilitate melanin synthesis using a wider variety of phenolic compounds found in natural environments.
Alternatively, the redox nature of PPO enzymes implies that they can be used to either polymerize or depolymerize complex substrates such as lignin, as clearly evidenced in fungal laccases (Thurston, 1994). In marine waters most of the organic matter is in the form of high molecular mass compounds of phenolic nature that can even inhibit microbial metabolism (Morita, 1986). These compounds are highly resistant to microbial degradation and hence the expression of the PPO activities might facilitate the degradation of these compounds and may give to the cell a competitive advantage when other more easily metabolizable substrates are depleted.

The regulation at the molecular level of PPO activities and melanin formation in M. mediterranea has been approached for the first time in this study. It has been shown that both PPOs are subjected to coordinate regulation. During the growth curve in complex medium, these activities are induced in stationary phase. The novel PpoS sensor histidine kinase, cloned and sequenced in this study, is involved in this regulation and allows maximal levels of enzymic activities. To go further in the characterization of the physiological relevance of PPO activities and melanin synthesis in $M$. mediterranea, the environmental signals sensed by PpoS and the response of $M$. mediterranea to stress conditions are under investigation.

\section{ACKNOWLEDGEMENTS}

This work was supported by grant BIO 2001-0140 from the CICYT, Spain. P. Lucas-Elío is the recipient of a predoctoral fellowship from the Fundación Séneca (Comunidad Autónoma de Murcia). We are grateful to Celia JiménezCervantes for critical suggestions. We also thank the DNA sequencing service of CIB, Madrid, Spain, for their excellent and rapid work.

\section{REFERENCES}

Alexeyev, M. F. \& Shokolenko, I. N. (1995). Mini-Tn10 transposon derivatives for insertion mutagenesis and gene delivery into the chromosome of Gram-negative bacteria. Gene 160, 59-62.

Appleby, J. L., Parkinson, J. S. \& Bourret, R. B. (1996). Signal transduction via the multi-step phosphorelay: not necessarily a road less traveled. Cell 86, 845-848.

Burbulys, D., Trach, K. A. \& Hoch, J. A. (1991). Initiation of sporulation in B. subtilis is controlled by a multicomponent phosphorelay. Cell 64, 542-552.

Chen, D. \& Patton, J. T. (2001). Reverse transcriptase adds nontemplated nucleotides to cDNAs during $5^{\prime}$-RACE and primer extension. Biotechniques 30, 572-582.

Chirgwin, J. M., Przybyla, A. E., MacDonald, R. J. \& Rutter, W. J. (1979). Isolation of biologically active ribonucleic acid from sources enriched in ribonuclease. Biochemistry 18, 5294-5299.

Cserzo, M., Wallin, E., Simon, I., von Heijne, G. \& Elofsson, A. (1997). Prediction of transmembrane alpha-helices in procaryotic membrane proteins: the Dense Alignment Surface method. Protein Eng 10, 673-676.

de Lorenzo, V., Herrero, M., Jakubzik, U. \& Timmis, K. N. (1990). Mini-Tn5 transposon derivatives for insertion mutagenesis, promoter probing, and chromosomal insertion of cloned DNA in gram-negative eubacteria. J Bacteriol 172, 6568-6572. 
Fabret, C., Feher, V. A. \& Hoch, J. A. (1999). Two-component signal transduction in Bacillus subtilis: how one organism sees its world. J Bacteriol 181, 1975-1983.

Faure, D., Bouillant, M. L. \& Bally, R. (1994). Isolation of Azospirillum lipoferum 4T Tn5 mutants affected in melanization and laccase activity. Appl Environ Microbiol 60, 3413-3415.

Fernández, E., Sanchez-Amat, A. \& Solano, F. (1999). Location and catalytic characteristics of a multipotent bacterial polyphenol oxidase. Pigment Cell Res 12, 331-339.

Givaudan, A., Effose, A., Faure, D., Potier, P., Bouillant, M. L. \& Bally, R. (1993). Polyphenol oxidase from Azospirillum lipoferum isolated from rice rhizosphere: evidence for laccase activity in non-motile strains of Azospirillum lipoferum. FEMS Microbiol Lett 108, 205-210.

Herrero, M., de Lorenzo, V. \& Timmis, K. N. (1990). Transposon vectors containing non-antibiotic resistance selection markers for cloning and stable chromosomal insertion of foreign genes in gram-negative bacteria. J Bacteriol 172, 6557-6567.

Hullo, M.-F., Moszer, I., Danchin, A. \& Martin-Verstraete, I. (2001). CotA of Bacillus subtilis is a copper-dependent laccase. $J$

Bacteriol 183, 5426-5430.

Kim, C., Lorenz, W. W., Hoopes, J. T. \& Dean, J. F. D. (2001). Oxidation of phenolate siderophores by the multicopper oxidase encoded by the Escherichia coli yacK gene. J Bacteriol 183, 4866-4875.

Lee, C. \& Bada, L. (1975). Amino acids in equatorial ocean water. Earth Plan Sci Lett 26, 61-68.

Lee, S. J. \& Gralla, J. D. (2001). Sigma38 $(r p o S)$ RNA polymerase promoter engagement via -10 region nucleotides. J Biol Chem 276, 30064-30071.

López-Serrano, D., Sanchez-Amat, A. \& Solano, F. (2002). Cloning and molecular characterization of a SDS-activated tyrosinase from Marinomonas mediterranea. Pigment Cell Res 15, 104-111.

Miller, J. H. (1992). A Short Course in Bacterial Genetics. Cold Spring Harbor, NY : Cold Spring Harbor Laboratory.

Morita, R. Y. (1986). Starvation survival: the normal mode of most bacteria in the ocean. Proc IV ISME, 242-248.

Mukhopadhyay, S., Audia, J. P., Roy, R. N. \& Schellhorn, H. E. (2000). Transcriptional induction of the conserved alternative sigma factor RpoS in Escherichia coli is dependent on BarA, a probable two-component regulator. Mol Microbiol 37, 371-381.
Sanchez-Amat, A. \& Solano, F. (1997). A pluripotent polyphenol oxidase from the melanogenic marine Alteromonas sp shares catalytic capabilities of tyrosinases and laccases. Biochem Biophys Res Commun 240, 787-792.

Sanchez-Amat, A., Lucas-Elío, P., Fernández, E., Garcia-Borrón, J. C. \& Solano, F. (2001). Molecular cloning and functional characterization of a unique multipotent polyphenol oxidase from Marinomonas mediterranea. Biochim Biophys Acta 1547, 104-116.

Solano, F. \& Sanchez-Amat, A. (1999). Studies on the phylogenetic relationships of melanogenic marine bacteria : proposal of Marinomonas mediterranea sp. nov. Int J Syst Bacteriol 49, 1241-1246.

Solano, F., García, E., Pérez de Egea, E. \& Sanchez-Amat, A. (1997). Isolation and characterization of strain MMB-1 (CECT 4803), a novel melanogenic marine bacterium. Appl Environ Microbiol 63, 3499-3506.

Solano, F., Lucas-Elío, P., Fernández, E. \& Sanchez-Amat, A. (2000). Marinomonas mediterranea MMB-1 transposon mutagenesis: isolation of a multipotent polyphenol oxidase mutant. J Bacteriol 182, 3754-3760.

Solano, F., Lucas-Elío, P., López-Serrano, D., Fernández, E. \& Sanchez-Amat, A. (2001). Dimethoxyphenol oxidase activity of different microbial blue multicopper proteins. FEMS Microbiol Lett 204, 175-181.

Stock, J. B., Ninfa, A. J. \& Stock, A. M. (1989). Protein phosphorylation and regulation of adaptative responses in bacteria. Microbiol Rev 53, 450-490.

Thurston, C. F. (1994). The structure and function of fungal laccases. Microbiology 140, 19-26.

Tsai, H. F., Wheeler, M. H., Chang, Y. C. \& Kwon-Chung, K. J. (1999). A developmentally regulated gene cluster involved in conidial pigment biosynthesis in Aspergillus fumigatus. $\mathrm{J} \mathrm{Bac-}$ teriol 181, 6469-6477.

Uhl, M. A. \& Miller, J. F. (2001). Integration of multiple domains in a two-component sensor protein: the Bordetella pertussis BvgAS phosphorelay. EMBO J 15, 1028-1036.

Williamson, P. R., Wakamatsu, K. \& Ito, S. (1998). Melanin biosynthesis in Cryptococcus neoformans. J Bacteriol 180, 1570-1572.

Received 4 March 2002; revised and accepted 11 April 2002. 